\title{
Efficacy of carprofen on conception rates in lactating dairy cows after subcutaneous or intrauterine administration at the time of breeding
}

\author{
W. Heuwieser, ${ }^{\star 1}$ M. Iwersen, ${ }^{\star}$ and L. Goetze† \\ *Sustainable Dairy Reproduction Program, Clinic for Animal Reproduction, Faculty of Veterinary Medicine, Freie Universität Berlin, \\ Koenigsweg 65, 14165 Berlin, Germany \\ †Pfizer Animal Health, Veterinary Medicine Research and Development, Ramsgate Road, Sandwich, Kent CT13 9NJ, United Kingdom
}

\begin{abstract}
Manipulation of the reproductive tract can cause inflammatory processes in the endometrium and release of cytokines and prostaglandins. It has been shown that $\mathrm{PGF}_{2 \alpha}$ has direct negative effects on embryonic survival and development. Treatment with nonsteroidal antiinflammatory drugs (e.g., ibuprofen lysinate, flunixin meglumine) might improve pregnancy rates after embryo transfer in recipient heifers. The primary objective of this study was to evaluate the effect of a nonsteroidal antiinflammatory drug on reproductive performance in lactating dairy cows when administered at the time of first-service artificial insemination (AI) based on the hypothesis that uterine manipulation during AI might be similarly intense compared with embryo transfer in its effect on prostaglandin release. A total of 970 cows (333 primiparous and 637 multiparous) from 17 Holstein dairy farms were enrolled. On the day of first AI, cows were randomly allocated to 1 of 3 treatment groups. Cows of group 1 received $1.4 \mathrm{mg} / \mathrm{kg}$ of body weight (BW) of carprofen subcutaneously immediately after AI (SC group). In group 2, $1.4 \mathrm{mg} / \mathrm{kg}$ of BW of carprofen was administered into the uterus using a sterile disposable catheter 12 to $24 \mathrm{~h}$ after AI (IU group). Animals of group 3 remained as untreated controls. First AI conception rate was similar for the SC group (42.2\%) compared with the untreated control group (45.1\%). A binary logistic regression model for the odds of conception at first AI revealed a negative effect of an intrauterine administration of carprofen on conception rate $(38.3 \%)$. Cows allocated to the IU group had a lower likelihood of being pregnant within $200 \mathrm{~d}$ in milk than cows in the control group. In summary, subcutaneous treatment with the nonsteroidal antiinflammatory drug carprofen at the time of AI did not influcence conception rate, whereas an intrauterine administration of carprofen 12 to $24 \mathrm{~h}$ after first AI
\end{abstract}

Received April 15, 2010.

Accepted September 19, 2010.

${ }^{1}$ Corresponding author: heuwieser.wolfgang@vetmed.fu-berlin.de had a negative effect on first-service conception rate in lactating dairy cows.

Key words: uterine manipulation, nonsteroidal antiinflammatory drug, first AI conception rate

\section{INTRODUCTION}

Reproductive performance in dairy cows is influenced by multiple factors such as transition cow management, metabolic and udder health, lameness, estrus detection, semen handling, and use of synchronization protocols (Lucy, 2001; Caraviello et al., 2006).

Manipulation of the reproductive tract can represent a trauma to the uterine endometrium causing subsequent inflammatory processes; that is, release of chemical mediators such as cytokines and prostaglandins. A 2-min uterine manipulation increased plasma concentration of 13,14-dihydro-15 keto prostaglandin $2 \alpha$ (PGFM) in cows at 35 d postpartum (Wann and Randel, 1990). In a more recent study the intensity of uterine manipulation necessary to conduct embryo transfer (ET) was scored on a scale from 1 (i.e., transfer requiring minimal manipulation of the genital tract) to 3 (i.e., transfer requiring extreme manipulation of the genital tract). Concentrations of $\mathrm{PGF}_{2 \alpha}$ were already increased following minimal manipulation during ET (Scenna et al., 2005). Both in vivo and in vitro studies provided sound evidence that $\mathrm{PGF}_{2 \alpha}$ has direct negative effects on embryonic survival or development (Buford et al., 1996; Seals et al., 1998).

Nonsteroidal antiinflammatory drugs (NSAID) block the synthesis of prostaglandins including $\mathrm{PGF}_{2 \alpha}$ via inhibition of the 2 isoforms of the enzyme cyclooxygenase (COX, EC 1.14.99.1), COX-1 and COX-2 (Anderson et al., 1990). These enzymes are the essential catalysts at the beginning of the synthesis of prostaglandins. Inhibition of $\mathrm{PGF}_{2 \alpha}$ secretion through NSAID has been demonstrated to increase reproductive performance after ET. Pregnancy rates after ET were higher in recipient heifers receiving either $5 \mathrm{mg}$ of ibuprofen lysinate $(82$ vs. $56 \%$ ) or $830 \mathrm{mg}$ of flunixin meglumine (FM, 65.3 vs. $60.2 \%$ ) compared with untreated control animals 
(Elli et al., 2001; Scenna et al., 2005). Although the timing of treatment relative to ET (immediately before vs. after transfer) did not affect reproductive performance, the difference in pregnancy rates was greater (64.2 vs. $53.5 \%)$ for lower quality embryos. The authors concluded that developmentally compromised embryos were most susceptible to deleterious effects of $\mathrm{PGF}_{2 \alpha}$ compared with high quality embryos (Scenna et al., 2005).

The suppressive effect of $\mathrm{FM}$ on $\mathrm{PGF}_{2 \alpha}$ synthesis reached its maximum $4 \mathrm{~h}$ after application and persisted for up to $8 \mathrm{~h}$ (Thun et al., 1993). The same authors suggested repeating administration every 4 to $6 \mathrm{~h}$ to ensure inhibition of prostaglandin synthesis for a longer period.

Carprofen also had antiinflammatory effects without selectivity in sheep (Cheng et al., 2002) and had an extended elimination half-life (ranging from 44.5 to 64 . 6h) compared with those reported for other NSAID such as FM (Ludwig et al., 1989). Commercially available products contain a racemic mixture of 2 enantiomeric isoforms of carprofen. Research in vitro demonstrated that the $\mathrm{S}(+)$-enantiomer is more selective for COX-2 than the $\mathrm{R}(-)$-enantiomer of carprofen (Ricketts et al., 1998).

Although some evidence exists suggesting that uterine manipulation is associated with the amount of $\mathrm{PGF}_{2 \alpha}$ secreted (Wann and Randel, 1990; Scenna et al., 2005), information is lacking on how uterine manipulation during $\mathrm{AI}$ affects concentrations of PGFM or $\mathrm{PGF}_{2 \alpha}$.

We hypothesize that uterine manipulation during AI and ET can be similarly intense in its effect on prostaglandin release because in both cases an instrument is passed through the cervical canal. Therefore, the overall objective of this study was to evaluate the effect of a COX inhibitor drug (carprofen) on reproductive performance in lactating dairy cows when administered at the time of first service. Specifically, we set out to (1) compare first-service conception rates between cows treated subcutaneously with a long-acting NSAID and untreated control cows, and (2) study the effect of NSAID administered into the uterus 12 to $24 \mathrm{~h}$ after AI on first-service conception rate.

\section{MATERIALS AND METHODS}

All procedures in this trial were conducted according to the International Cooperation on Harmonization of Technical Requirements for Registration of Veterinary Medicinal Products (2000) regulations relating to Good Clinical Practice and Clinical Trials (GCP). A total of 970 cows (333 primiparous and 637 multiparous) from 17 Holstein dairy farms located in Brandenburg, Germany, were enrolled between October and December 2007.
The farms had been identified in advance to ensure a valid test permit for each herd and informed consent of the farm manager. Inclusion criteria were herd size (>100 cows), participation in the German Dairy Herd Improvement Organization (Landeskontrollverband Brandenburg, Waldsieversdorf, Germany), all breedings through AI, and an electronic record-keeping system. The herds ranged from 180 to 630 milking cows and the rolling herd averages were about $10,000 \mathrm{~kg}$ of milk per cow per year. All lactating dairy cows were housed in freestall facilities and milked twice a day. Reproductive management varied among farms. All dairies relied on estrus detection for their breedings and were serviced by an AI technician employed by one company (Rinderproduktion Berlin-Brandenburg GmbH, Groß Kreutz, Germany). Synchronization protocols were not implemented. Seven AI technicians were involved in the study, each servicing from 1 to 3 study sites.

On the day of first insemination, cows were randomly allocated to 1 of 3 treatment groups using a random treatment allocation plan generated before the initiation of the trial using a random number generator (Excel 2003, Microsoft Corp., Redmond, WA). Each of the AI technicians was supplied with an allocation plan for each of their client farms. Cows of group 1 received $1.4 \mathrm{mg} / \mathrm{kg}$ of BW of carprofen (Rimadyl, Pfizer Animal Health, Berlin, Germany) subcutaneously (SC, $\mathrm{n}=325)$ immediately after AI. In group $2,1.4 \mathrm{mg} / \mathrm{kg}$ of BW of carprofen was administered into the uterus using a sterile disposable catheter 12 to $24 \mathrm{~h}$ after AI $(\mathbf{I U}, \mathrm{n}=317)$. Animals of group $3(\mathbf{C O N}, \mathrm{n}=327)$ remained as untreated controls. Treatment was not documented for 1 cow.

Pregnancy was diagnosed on d 39 to 48 after AI by transrectal palpation carried out by a veterinarian who was unaware of the treatment allocation. This diagnosis was confirmed at approximately $100 \mathrm{~d}$ after insemination. Reproductive performance was characterized by first AI conception rate (number of cows pregnant after first AI divided by number of cows inseminated $\times 100$ ) as the primary outcome variable (i.e., only for animals detected in estrus and inseminated) and days to first AI.

Furthermore, days to pregnancy, all-service conception rate (number of cows pregnant after all AI divided by number of cows inseminated $\times 100$ ), and pregnancy rate at 200 DIM (number of cows documented to be pregnant by 200 DIM divided by number of cows enrolled $\times 100)$ were calculated from 11 farms for a subset of cows $(\mathrm{n}=543)$. All treatments and diagnoses were documented on case report forms (CRF). At the end of the study, CRF were checked for compliance. Cows with incomplete treatments were retrospectively withdrawn from the study. For quality assurance of raw 
Table 1. Descriptive data of reproductive performance parameters for cows treated with $1.4 \mathrm{mg}$ of carprofen $/ \mathrm{kg}$ of BW subcutaneously or into the uterus and untreated control cows

\begin{tabular}{|c|c|c|c|}
\hline \multirow[b]{2}{*}{ Outcome } & \multicolumn{3}{|c|}{ Treatment group } \\
\hline & $\begin{array}{c}\text { Subcutaneous } \\
\mathrm{n}=325\end{array}$ & $\begin{array}{c}\text { Intrauterine } \\
\mathrm{n}=313\end{array}$ & $\begin{array}{l}\text { Control } \\
\mathrm{n}=326\end{array}$ \\
\hline Median days open (IR) & $\begin{array}{l}71.0 \\
(55.0-96.0)\end{array}$ & $\begin{array}{l}74.5 \\
(58.3-102.8)\end{array}$ & $\begin{array}{l}74.0 \\
(58.0-99.5)\end{array}$ \\
\hline Pregnancy rate at $200 \mathrm{~d}, \%(95 \% \mathrm{CI})$ & $\begin{array}{l}86.6 \\
(81.1-91.5)\end{array}$ & $\begin{array}{l}76.4 \\
(69.5-82.5)\end{array}$ & $\begin{array}{l}87.7 \\
(82.5-92.3)\end{array}$ \\
\hline
\end{tabular}

${ }^{\mathrm{a}, \mathrm{b}}$ Values with different superscripts in the same row differ $(P=0.08)$.

${ }^{1} \mathrm{IR}=$ interquartile range.

data and CRF, an online monitoring tool (DrNet Study Monitor, Berlin, Germany) was used. Sample size for this study (statistical power $80 \%$ ) was calculated as 320 cows per group for an estimated first AI conception rate of $35 \%$ to find proportions of $<27 \%$ and $>43 \%$ as significant $(P<0.05)$.

\section{Statistical Analysis}

Data were analyzed using SPSS (version 16.0, SPSS Inc., Munich, Germany). Binary logistic regression models were calculated for the risk of conception at first AI as the primary outcome variable. Survival analysis for the probability of pregnancy within 200 DIM was performed using Cox regression, censoring cows that were not pregnant. For logistic regression models as well as for survival analysis, group $(1=\mathrm{SC}, 2=\mathrm{IU}, 3$ $=\mathrm{CON})$, parity class $(0=$ primiparous, $1=$ multiparous), AI technician, and herd were included as factors. Group CON was chosen as reference for covariate group. Adjusted odds ratios, hazard ratios, confidence intervals, and $P$-values are reported. For logistic regression as well as for survival analyses, CI was set at $95 \%$. For all statistical analyses level of significance was set at $\alpha=0.05$.

\section{RESULTS AND DISCUSSION}

We hypothesized that the administration of a COX inhibitor drug (carprofen) at the time of AI could have a similarly positive effect on reproductive performance of dairy cows as has been demonstrated for recipient heifers after ET (Elli et al., 2001; Scenna et al., 2005). The results of this study do not provide any evidence of a positive effect of the NSAID carprofen on conception rates in lactating dairy cows administered s.c. at the time of AI.

For the analysis of the primary outcome variable, $964(99.4 \%)$ cows could be used (Table 1$)$. Six cows
$(0.6 \%)$ had to be excluded from the analyses because of missing treatment information $(\mathrm{n}=1)$ or protocol noncompliance $(\mathrm{n}=5)$. Median time from calving to first AI for all cows enrolled was $69 \mathrm{~d}$ (interquartile range: 56.0-91.0). For the subset of farms $(\mathrm{n}=11)$ overall submission rate for AI was $23.7 \pm 7.7 \%$.

First AI conception rate was similar for the SC group $(42.2 \%, P=0.45)$ and numerically lower in the IU group $(38.3 \%, P=0.08)$ compared with the untreated control group (45.1\%; Figure 1). A binary logistic regression model for the risk of conception at first AI revealed a negative effect of intrauterine administration of carprofen on conception rate (Table $2 ; P=0.08$ ). Because we did not utilize a fourth group of cows treated with an intrauterine infusion of a control fluid at the same time as the carprofen was infused (i.e., 12 to $24 \mathrm{~h}$ after AI), it remains unclear if this negative effect was caused by toxic properties of the NSAID itself or the infusion process of a fluid in general. It is possible that the carprofen in the pharmacological formulation used was not absorbed into the endometrium and thus could not prevent uterine prostaglandin release. Therefore, the additional uterine manipulation necessary to administer the carprofen into the uterus of the cows in the IU group could have caused prostaglandin release, disrupting preimplantation processes or exerting an embryo toxic effect (Hockett et al., 2004; Scenna et al., 2004). Furthermore, it is possible that the procedure of passing a catheter for administering the fluid into the uterus $1 \mathrm{~d}$ after insemination caused inflammation or entry of pathogens detrimental to fertility. Findings from a previous trial, however, studying the effect of collecting endometrial samples with the cytobrush technique $4 \mathrm{~h}$ after AI on first AI conception rate do not support this hypothesis (Kaufmann et al., 2009). First AI conception rate was $43.3 \%$ for cows $(\mathrm{n}=201)$ examined with the cytobrush technique and $41.7 \%$ for cows $(\mathrm{n}=103)$ with no sample taken after AI $(P>0.05)$. The results 


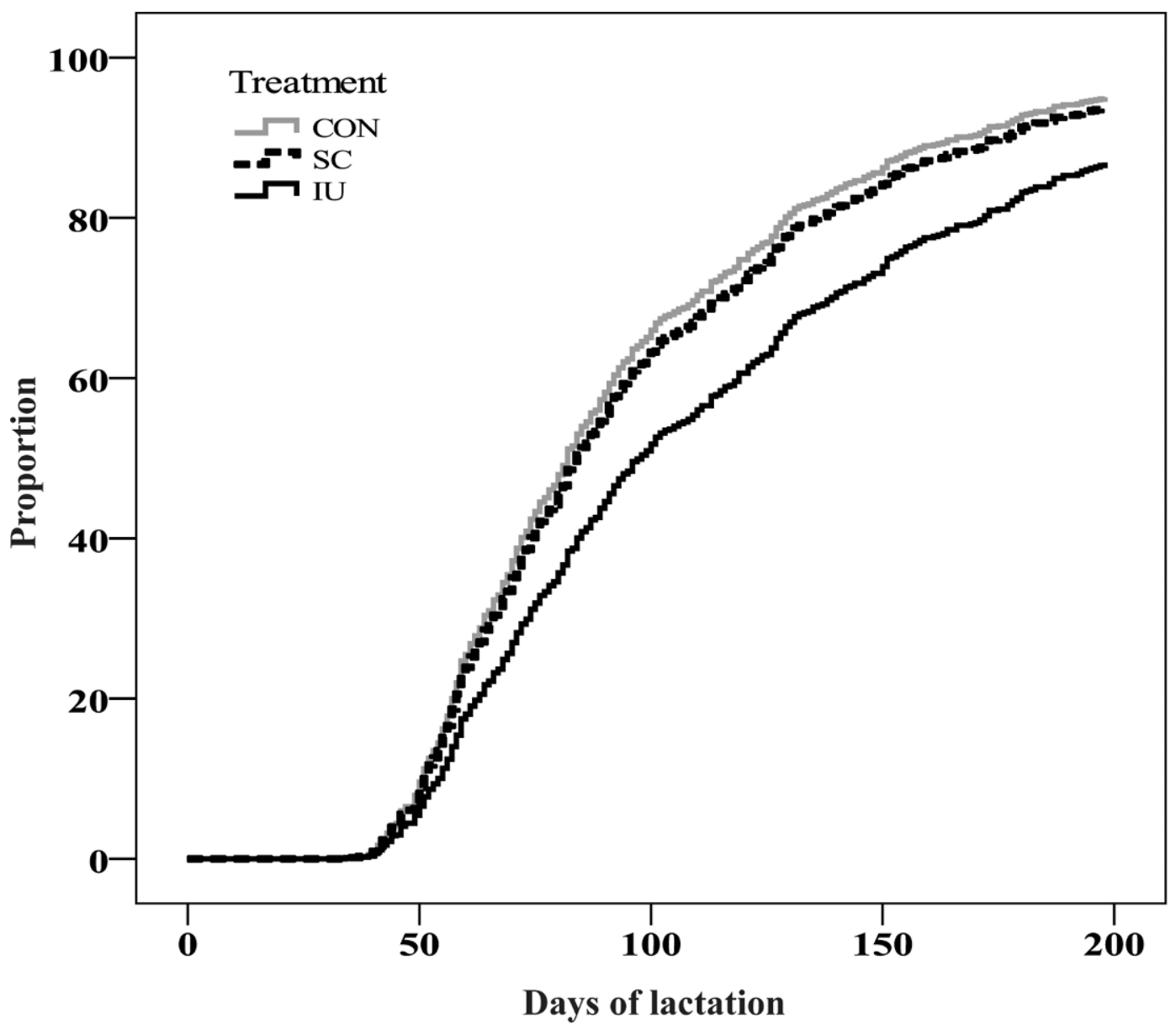

Figure 1. Proportion of pregnant cows for cows treated with carprofen subcutaneously (SC) or into the uterus (IU) and untreated (CON) control cows over $200 \mathrm{~d}$ of lactation.

of the 2 studies, however, are not directly comparable because timing between AI and passing the catheter was different ( $4 \mathrm{~h}$ vs. 12 to $24 \mathrm{~h}$ ).

Primiparous cows were significantly more likely to become pregnant than multiparous cows $(P<0.01)$ as has been reported previously (Tenhagen et al., 2004). Conception rate after first AI was affected by a herd $x$ AI technician interaction $(P=0.04)$.

Descriptive reproductive performance traits derived from outcomes of second and greater inseminations up to 200 DIM could be obtained from 11 farms providing a total of 543 cows. Table 3 shows the results of the survival analyses (Cox regression) for the odds of pregnancy within 200 DIM for this subset of cows. Group $\mathrm{CON}$ and $<55$ median days at first AI were chosen as the reference factors for treatment group and interval to first AI, respectively. Again, cows allocated to the IU group had a lower likelihood of being pregnant within 200 DIM than cows in the control group $(P<0.01)$. Besides treatment group, the hazard for pregnancy was affected by median days to AI and parity, but was not affected by herd and technician. The odds for pregnancy were lower for treated cows compared with untreated control cows and higher for primiparous cows compared with multiparous cows.

Pregnancy diagnosis (PD) was performed once on $\mathrm{d}$ 39 to 48 after AI by transrectal palpation. A second PD to monitor pregnancy losses between first PD and 100 DIM was not conducted. Of cows diagnosed as pregnant at first PD $(\mathrm{n}=244)$, only 11 cows $(2.9 \%)$ were re-inseminated between 40 and 100 DIM. These data indicate that pregnancy losses were not a predominant problem of the participating dairy farms.

Meloxicam treatment on d 15 after insemination decreased pregnancy rates in heifers significantly (Erdem and Guzeloglu, 2008). The authors hypothesized that a longer inhibition of prostaglandin $\mathrm{H}$ synthase activity interfered with the preimplantation process. Our data demonstrate that NSAID administered s.c. at the time of AI do not affect reproductive performance. Cows 
Table 2. Results of binary logistic regression analysis for the risk of conception after first AI in cows treated with $1.4 \mathrm{mg}$ of carprofen/kg of BW subcutaneously or into the uterus and untreated control cows including treatment group, median days to AI, parity, AI technician, and herd as covariates $(\mathrm{n}=964)$

\begin{tabular}{lccc}
\hline & \multicolumn{3}{c}{ Conceiving after first AI } \\
\cline { 2 - 4 } & $\begin{array}{c}\text { Odds } \\
\text { ratio }\end{array}$ & $95 \%$ & \\
Factor & & CI & 0.22 \\
\hline Treatment group & & \\
$\quad$ Control & & Referent & 0.48 \\
Subcutaneous & 0.89 & $0.65-1.22$ & 0.08 \\
$\quad$ Intrauterine & 0.75 & $0.55-1.04$ & 0.13 \\
Median days to AI & & & 0.86 \\
$\quad$ 55 DIM & & Referent & 0.19 \\
$56-78$ DIM & 1.03 & $0.73-1.46$ & 0.05 \\
$79-101$ DIM & 1.31 & $0.87-1.95$ & $<0.01$ \\
$>101$ DIM & 1.50 & $1.00-2.25$ & 0.06 \\
Parity class & 0.62 & $0.48-0.82$ & 0.07 \\
AI technician & 0.77 & $0.59-1.01$ & 0.04 \\
Herd & 0.91 & $0.81-1.01$ & 0.09 \\
Herd $\times$ AI technician & 1.02 & $1.00-1.05$ & \\
Constant & 3.06 & & \\
\hline
\end{tabular}

${ }^{1}$ Cows received $1.4 \mathrm{mg} / \mathrm{kg}$ of BW of carprofen subcutaneously immediately after AI, or into the uterus 12 to $24 \mathrm{~h}$ after $\mathrm{AI}$, or remained untreated.

${ }^{2}$ Parity class: $0=$ primiparous, $1=$ multiparous.

of the control group $(45.1 \%)$ and cows treated subcutaneously with carprofen $(42.2 \%)$ had similar first AI conception rates.

Long-acting NSAID such as carprofen and meloxicam have been recommended as additional treatments for cows with clinical mastitis. Several positive effects have been demonstrated such as improved general clinical condition by effective antipyrexia and restoration of reticulorumen motility in cows with Escherichia coli mastitis (Vangroenweghe et al., 2005) and a lower SCC and a reduced risk of removal from the herd (Mc-
Dougall et al., 2009). Our data support evidence that carprofen administered s.c. at the time of breeding for the treatment of inflammatory diseases (i.e., clinical mastitis or lameness) does not compromise reproductive performance.

\section{CONCLUSIONS}

First-service conception rate was not influenced by the NSAID carprofen administered s.c. at the time of first AI. Intrauterine administration of carprofen 12

Table 3. Results of the survival analyses (Cox regression) for the odds of pregnancy within 200 DIM in cows treated with $1.4 \mathrm{mg}$ of carprofen/ $\mathrm{kg}$ of BW subcutaneously or into the uterus and untreated control cows (n $=543)$

\begin{tabular}{|c|c|c|c|}
\hline \multirow[b]{2}{*}{ Factor } & \multicolumn{3}{|c|}{ Pregnancy } \\
\hline & $\begin{array}{c}\text { Hazard } \\
\text { ratio }\end{array}$ & $\begin{array}{c}95 \% \\
\text { CI }\end{array}$ & $P$-value \\
\hline Treatment group $^{1}$ & & & $<0.01$ \\
\hline Control & & Referent & \\
\hline Subcutaneous & 0.96 & $0.76-1.21$ & 0.73 \\
\hline Intrauterine & 0.68 & $0.53-0.87$ & $<0.01$ \\
\hline Median days to AI & & & $<0.01$ \\
\hline$<55$ DIM & & Referent & \\
\hline 56-78 DIM & 0.59 & $0.44-0.79$ & $<0.01$ \\
\hline 79-101 DIM & 0.49 & $0.36-0.67$ & $<0.01$ \\
\hline >101 DIM & 0.26 & $0.19-0.36$ & $<0.01$ \\
\hline Parity class $^{2}$ & 0.80 & $0.66-0.98$ & 0.03 \\
\hline AI technician & 0.99 & $0.80-1.23$ & 0.93 \\
\hline Herd & 1.00 & $0.92-1.08$ & 0.91 \\
\hline Herd $\times$ AI technician & 1.00 & $0.98-1.02$ & 0.93 \\
\hline
\end{tabular}

${ }^{1}$ Cows received $1.4 \mathrm{mg} / \mathrm{kg}$ of BW of carprofen subcutaneously immediately after AI or into the uterus 12 to 24 $\mathrm{h}$ after $\mathrm{AI}$, or remained untreated.

${ }^{2}$ Parity class: $0=$ primiparous, $1=$ multiparous. 
to $24 \mathrm{~h}$ after first $\mathrm{AI}$, however, tended $(P>0.08)$ to have a negative effect on first-service conception rate. Additional research is warranted to evaluate the effect of NSAID for the treatment of cows diagnosed with subclinical endometritis before AI.

\section{ACKNOWLEDGMENTS}

We thank the $7 \mathrm{AI}$ technicians for their valuable support in conducting this study. The authors also gratefully acknowledge the cooperation with the owners, the staff of the farms, and Rinderproduktion Berlin-Brandenburg GmbH (Groß Kreutz, Germany). This project was funded by Pfizer Animal Health, Veterinary Medicine Research and Development, UK, and by Tiergyn Berlin e.V. We thank Frau Doris Forderung (Clinic for Animal Reproduction, Faculty of Veterinary Medicine, Freie Universität Berlin, Germany) for technical assistance.

\section{REFERENCES}

Anderson, K. L., C. A. Neff-Davis, L. E. Davis, and V. D. Bass. 1990. Pharmacokinetics of flunixin meglumine in lactating cattle after single and multiple intramuscular and intravenous administrations. Am. J. Vet. Res. 51:1464-1467.

Buford, W. I., N. Ahmad, F. N. Schrick, R. L. Butcher, P. E. Lewis, and E. K. Inskeep. 1996. Embryotoxicity of a regressing corpus luteum in beef cows supplemented with progestogen. Biol. Reprod. 54:531-537.

Caraviello, D. Z., K. A. Weigel, P. M. Fricke, M. C. Wiltbank, M. J. Florent, N. B. Cook, K. V. Nordlund, N. R. Zwald, and C. L. Rawson. 2006. Survey of management practices on reproductive performance of dairy cattle on large US commercial farms. J. Dairy Sci. 89:4723-4735.

Cheng, Z., A. Nolan, and Q. A. McKellar. 2002. Anti-inflammatory effects of carprofen, carprofen enantiomers, and N(G)-nitro-L-arginine methyl ester in sheep. Am. J. Vet. Res. 63:782-788.

Elli, M., B. Gaffuri, A. Frigerio, M. Zanardelli, D. Convini, M. Dandiani, and M. Vignali. 2001. Effect of a single dose of ibuprofen lysinate before embryo transfer on pregnancy rates in cows. Reproduction 121:151-154.

Erdem, H., and A. Guzeloglu. 2008. Effect of meloxicam treatment during early pregnancy in Holstein heifers. Reprod. Domest. Anim. 45:625-628.

Hockett, M. E., N. R. Rohrbach, and F. N. Schrick. 2004. Alterations in embryo development in progestogen-supplemented cows administered prostaglandin F2. Prostaglandins Other Lipid Mediat. $73: 227-236$

International Cooperation on Harmonisation of Technical Requirements for Registration of Veterinary Medicinal Products. 2000. K. Hellmann, and I. Radeloff, ed. VICH, Brussels, Belgium.

Kaufmann, T. B., M. Drillich, B. A. Tenhagen, D. Forderung, and W. Heuwieser. 2009. Prevalence of bovine subclinical endometritis $4 \mathrm{~h}$ after insemination and its effects on first service conception rate. Theriogenology 71:385-391.

Lucy, M. C. 2001. Reproductive loss in high-producing dairy cattle: Where will it end? J. Dairy Sci. 84:1277-1293.

Ludwig, B., J. C. Jordan, W. F. Rehm, and R. Thun. 1989. Carprofen in veterinary medicine. I. Plasma disposition, milk excretion and tolerance in milk-producing cows. Schweiz. Arch. Tierheilkd. 131:99-106.

McDougall, S., M. A. Bryan, and R. M. Tiddy. 2009. Effect of treatment with the nonsteroidal antiinflammatory meloxicam on milk production, somatic cell count, probability of re-treatment,and culling of dairy cows with mild clinical mastitis. J. Dairy Sci. 92:4421-4431.

Ricketts, A. P., K. M. Lundy, and S. B. Seibel. 1998. Evaluation of selective inhibition of canine cyclooxygenase 1 and 2 by carprofen and other nonsteroidal anti-inflammatory drugs. Am. J. Vet. Res. 59:1441-1446.

Scenna, F. N., J. L. Edwards, N. R. Rohrbach, M. E. Hockett, A. M. Saxton, and F. N. Schrick. 2004. Detrimental effects of prostaglandin F2 alpha on preimplantation bovine embryos. Prostaglandins Other Lipid Mediat. 73:215-226.

Scenna, F. N., M. E. Hocket, T. M. Towns, A. M. Saxton, N. R. Rohrbach, M. E. Wehrmann, and F. N. Schrick. 2005. Influence of a prostaglandin synthesis inhibitor administered at embryo transfer on pregnancy rates of recipient heifers. Prostaglandins Other Lipid Mediat. 78:38-45.

Seals, R. C., J. W. Lemaster, F. M. Hopkins, and F. N. Schrick. 1998. Effects of elevated concentrations of prostaglandin F2 alpha on pregnancy rates in progestogen supplemented cattle. Prostaglandins Other Lipid Mediat. 56:377-389.

Tenhagen, B. A., R. Surholt, M. Wittke, C. Vogel, M. Drillich, and W. Heuwieser. 2004. Use of Ovsynch in dairy herds - Differences between primiparous and multiparous cows. Anim. Reprod. Sci. 81:1-11.

Thun, R., H. Kundig, K. Zerobin, H. Kindahl, B. K. Gustafsson, and W. Ziegler. 1993. Uterine motility of cattle during late pregnancy, labor and puerperium. III. Use of flunixin meglumine and endocrine changes. Schweiz. Arch. Tierheilkd. 135:333-344. (In German)

Vangroenweghe, F., L. Duchateau, P. Boutet, P. Lekeux, P. Rainard, M. J. Paape, and C. Burvenich. 2005. Effect of carprofen treatment following experimentally induced Escherichia coli mastitis in primiparous cows. J. Dairy Sci. 88:2361-2376.

Wann, R. A., and R. D. Randel. 1990. Effect of uterine manipulation 35 days after parturition on plasma concentrations of 13,14-dihydro-15-keto prostaglandin F2 in multiparous and primiparous Brahman cows. J. Anim. Sci. 68:1389-1394. 